\title{
Improving resolution and understanding controls on GPR response in carbonate strata: Implications for attribute analysis
}

\author{
Evan K. Franseen, Alan P. Byrnes, Jianghal XIa, and Richard D. Miller, Kansas Geological Survey, Lawrence, USA
}

For groundwater, and shallow stratigraphic studies have demonstrated and advanced the usefulness of ground-penetrating radar (GPR) in lithified and unconsolidated sedimentary deposits (e.g., see Neal, 2004 and references therein). Despite the advances, important questions still remain on factors that control the actual appearance and characteristics of GPR reflections and diffractions in any given setting.

A northeast Kansas quarry with exposures of layered Pennsylvanian carbonates (limestone, dolomite) and interbedded shale was selected to conduct experiments within a 3D grid. Our research incorporated several strategies and techniques not previously attempted to groundtruth GPR interpretation and determine controls on GPR reflection events. The experiments and initial results of our study that have implications for GPR applications to the rock record in general are:

1) Deterministic deconvolution of GPR data using the GPR instrument wavelet acquired in air eliminates narrowband source wavelet interference and results in clearer depiction of geologic features. There is a high degree of direct correlation of GPR reflections with bedding and lithologic changes, even for features that approach the theoretical resolution limits. Out-of-plane effects, multiples, and other noise on GPR data are minimal or nonexistent in this setting using deterministic deconvolution in the processing flow.

2) Petrographic data and petrophysical measurements are critical for determining which factors most influence dielectric constants. The similarity in dielectric constants between clays and carbonate rocks at the study site indicates that mineralogy alone cannot account for the strong reflections that occur. Petrophysical properties of the rocks in all layers are highly correlated including permeability with porosity and porosity with grain density (reflecting dolomitization). The strong GPR reflections at shale bed contacts are interpreted to result from the higher porosity in the carbonates associated with dolomitization of the original limestone and high water saturations associated with perched water on the shale beds. This result underscores the importance of including study of diagenetic effects in carbonate settings, which can be significant for GPR response.

3) The high degree of direct correlation of GPR reflections with geologic features and rock properties provides the opportunity to do forward modeling. Results from a volumetric-type dielectric mixing (time-propagation) model of the strata at the quarry site confirm that this modeling approach is sufficiently accurate for largerscale forward modeling. Forward modeling results compared to and calibrated with actual GPR response from the grid, can in turn be used for inversely modeling expected reflection coefficients, two-way traveltimes, and vertical and spatial imaging. The inverse modeling results can be used to predict lithology and rock properties based on GPR attributes away from control points.

Setting and methods. The study site is in the Shawnee Rock

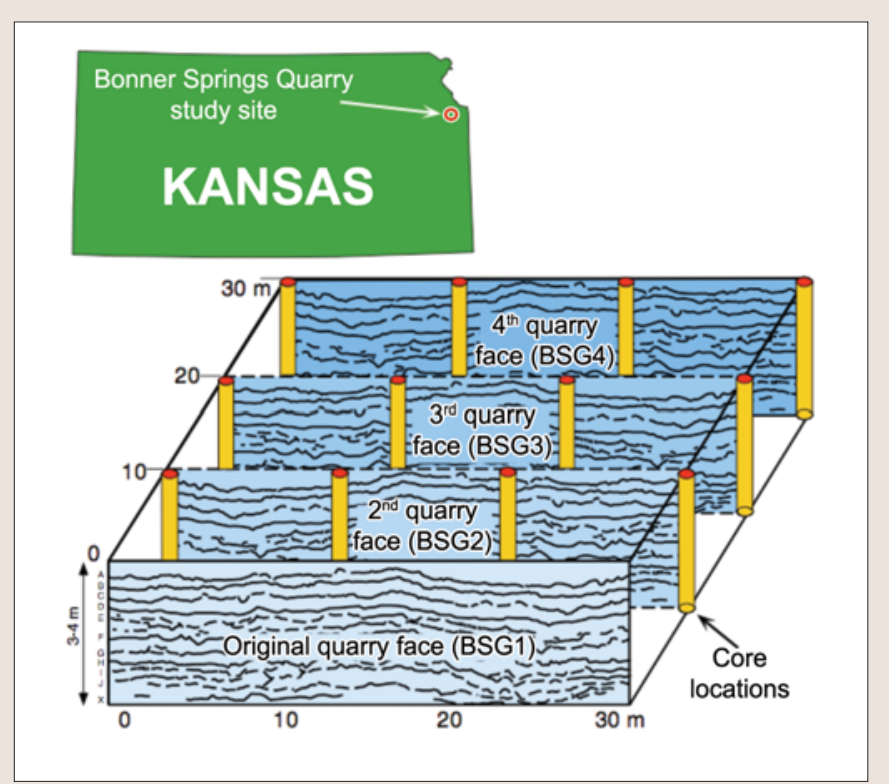

Figure 1. Location and line drawing showing the $30 \mathrm{~m} \times 30 \mathrm{~m} 2 \mathrm{D}$ grid on a flat bench behind an initial quarry face (BSG1) approximately 2.7-3.5 m (9-12 ft) thick. Successive quarry face exposures and 12 cores provided initial groundtruth for GPR interpretation.

Company quarry near Bonner Springs, Kansas (Figure 1). A bench on the upper Farley Member (Pennsylvanian) was selected for the study grid. Upper Farley strata are vertically exposed for approximately $3 \mathrm{~m}$ on the quarry face and characterized by medium $(<0.15 \mathrm{~m})$ to thick $(0.3-0.9 \mathrm{~m})$ beds of carbonate separated by thin $(<2.5 \mathrm{~cm})$ shale partings and stylocumulates (material that passively accumulated as insoluble residue along a pressure-solution surface). The shale partings and stylocumulates commonly diffuse into adjacent limestone over a scale of $0.5-7.5 \mathrm{~cm}$. The carbonate beds are well-cemented skeletal wackestone and packstone consisting predominantly of phylloid algae, bryozoans, brachiopods, and, locally, algal-coated grains (Osagia) in a matrix of micrite, peloidal micrite, and microspar. They are interpreted to have been deposited in low-to-moderateenergy marine environments (McKirahan et al., 2000). A characteristic of upper Farley strata is the lateral continuity of the generally horizontal (and wavy horizontal) bedding. Shale partings and stylocumulates at bedding planes are generally present as traced laterally, but may be absent locally.

We initially collected GPR data on a flat bench immediately behind a quarry face (BSG1) along a two-dimensional grid $30 \times 30 \mathrm{~m}$ (Figure 1). Seven lines of GPR data were taken parallel to the quarry face and seven lines perpendicular to the quarry face, each separated by $5 \mathrm{~m}$. GPR data were collected using 50-, 100-, 200-, and $400 \mathrm{MHz}$ antennas. We acquired a 128-fold vertical stack every $0.1 \mathrm{~m}$ along each line with the $400-\mathrm{MHz}$ antennas while maintaining a fixed source and receiver separation of $0.6 \mathrm{~m}$. A perpendicularbroadside antenna orientation was employed to give the radar section more of a two-dimensional slice through the subsurface (Annan, 1996).

Initial correlation of GPR response to the rock proper- 


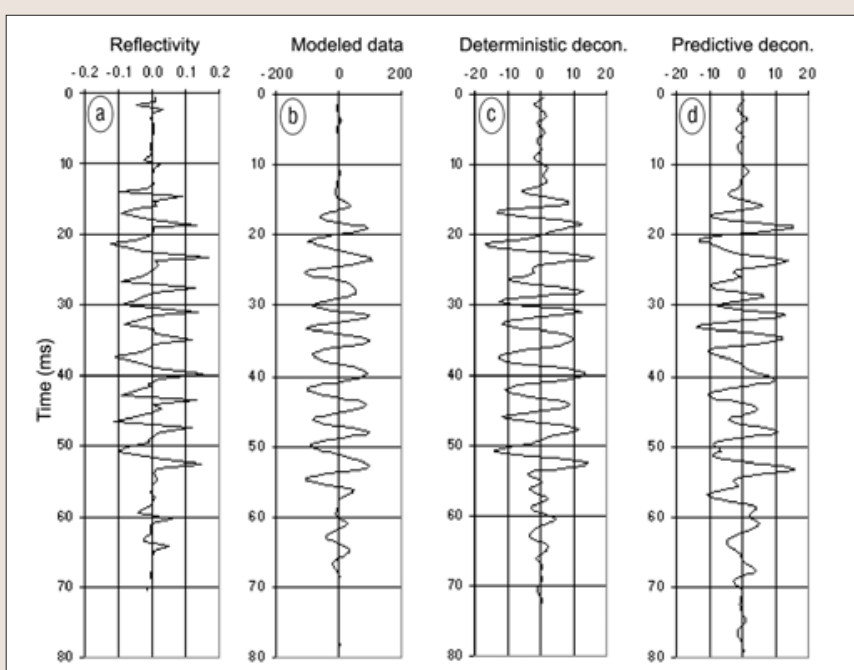

Figure 2. (a) Reflectivity model and synthetic GPR traces (from Xia et al., 2003). The reflectivity model (a) was generated from bulk dielectric constants. The synthetic GPR reflection data $(b)$ were calculated from the reflectivity model using the convolution model. Traces after the deterministic deconvolution (c) and the predictive deconvolution (d) are shown for comparison.

ties was accomplished by mapping geologic features exposed as quarry operators blasted back at 10-m intervals in coordination with our three-dimensional grid and borehole (core) locations (Figure 1). Cores and outcrops were sampled to obtain lithologic, diagenetic, porosity, hydraulic permeability, minipermeameter, water saturation, and dielectric constant data.

We devised a new technique whereby steel rods $1.5 \mathrm{~m}$ in length and $4.4 \mathrm{~cm}$ in diameter were inserted into holes drilled horizontally into the quarry face to provide direct groundtruth of reflections and reflectors. A total of 78 horizontal holes with inserted rods were located at key spots on three exposed quarry faces, BSG1, BSG2, and BSG3 (Figure 1). Diagnostic reflections/diffractions from the rods on GPR data provided the exact locations of the subsurface being imaged, which, through comparisons to the measured rod locations in the quarry face, provide exact correlation of reflections to reflectors. The steel bars provided critical information for: (1) correlation between reflections on GPR data and geologic features exposed in the quarry face, (2) GPR resolution limits, (3) accuracy of velocities calculated from common midpoint (CMP) data, and (4) identifying multiples.

Deterministic deconvolution. Interpretation of subtle geologic features in GPR data depends on data resolution. Ringing (related to bandwidth) in GPR sections, as in seismic sections, negatively impacts resolution and therefore needs to be identified and reduced or eliminated. Deconvolution is essential for increasing the temporal resolution of seismic and GPR data. It is especially important for shallow GPR stratigraphic studies where optimal resolution for interpretation is critical. A few studies have successfully applied statistical deconvolution to GPR data (Turner, 1994; Todoeschuck et al., 1992; Neves et al., 1995; Gottsche et al., 1994; Porsani and Ursin, 1996; Moran et al., 2000). However, reflection multiples that are unaccounted for, or assumptions inherent to most statistical deconvolution models (e.g., assuming reflectivity is a random process) complicate application of these deconvolution approaches to GPR data collected at field sites. The need to develop new strategies that improve the resolution of GPR data in shal- low sedimentary rock studies prompted us to focus on a method using deterministic deconvolution to eliminate (partly) ringing effects in GPR data. A convolution model was developed using the GPR instrument wavelet acquired in air. The best deconvolution results, which are confirmed by the conductive rods for the $400-\mathrm{MHz}$ antenna tests, were observed for wavelets acquired when the transmitter and receiver were separated by $0.3 \mathrm{~m}$. The convolution model relies on the fact that the source wavelet does not change from place to place or as a function of antenna-ground coupling. Effects of antenna ground coupling and EM energy propagating in the Earth result in an unknown wavelet, the effects of which become significant in high dielectric-loss media such as wet soil. Under such conditions acquisition of this wavelet is difficult and site dependent and statistical methods are necessary to remove it (e.g., Turner, 1994). However, when GPR data are acquired in low dielectric-loss media like snow or carbonate strata, such as at our study site, effects of the unknown wavelet may be negligible. When the source wavelet is known, it can be removed using the deterministic deconvolution method as described by Yilmaz (1987).

Tests on synthetic GPR data showed obvious differences between the deterministic deconvolution and the predictive deconvolution. To generate synthetic data, we measured matrix composition to establish component dielectric constants and measured dielectric constants at a centimeter scale from rock samples collected at the test site. Component dielectric constants for mineralogy, water, air, and relative concentrations were used to calculate bulk dielectric constants using the time propagation model (Knoll, 1996; also see discussion later in this paper) that has been previously shown to accurately predict bulk properties for the types of rocks in this study (Martinez and Byrnes, 2001). A reflectivity model (Figure 2a) was generated solely from the bulk dielectric constants. Synthetic GPR reflection data (Figure $2 \mathrm{~b})$ were produced using the convolution model. Deterministic deconvolution was applied to the synthetic data (Figure 2c). The reflectivity series was recovered (except for a scaling factor) as expected because the source wavelet is known. Predictive deconvolution was also applied to the synthetic data with different predictive lags (from 1.5 to 6 ns). A filter length of 6 ns was chosen to be consistent with the length of the source wavelet. The best results after the predictive deconvolution (a predictive lag of $3 \mathrm{~ns}$ ) are shown in Figure 2d. Because the predictive deconvolution estimates the source wavelet based on the assumption that reflectivity is a random process, predictive deconvolution was not as effective and the recovered reflectivity series was not as accurate in comparison with the deterministic deconvolution where the source wavelet is known.

In all cases, removal of the source wavelet has the potential to produce the highest possible resolution independent of data characteristics. The following section provides examples of the successful application of deterministic deconvolution in our study. For details describing methodologies and experiments used in our study for applying deterministic deconvolution, see Xia et al. (2003 and 2004).

GPR results from the study site. A variety of experiments were conducted using steel rods inserted into holes drilled horizontally into the quarry face. The steel rods were variously arranged vertically or laterally along horizons in the quarry face exposures to determine the nature of GPR response and for use in accurately calibrating GPR response to known locations as measured on the quarry face. The steel rods proved valuable for verification that including a deter- 


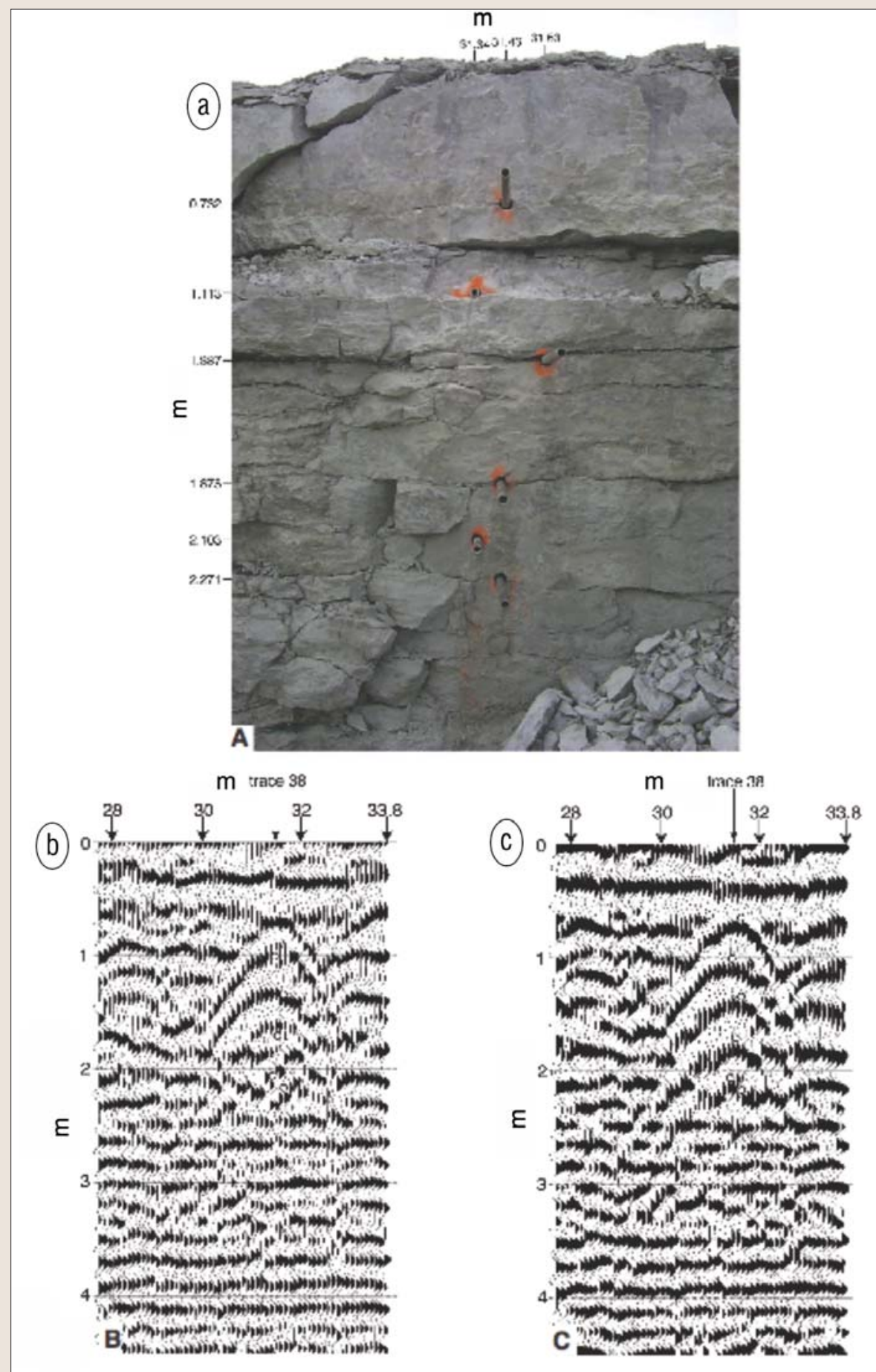

Figure 3. Outcrop photo of part of a quarry face containing six horizontal holes with steel rods, (b) 400-MHz GPR data, trapezoidal bandpass (80/130-400/500 MHz) filtered and scaled (10-ns AGC) along a 6-m line on the bench $1 \mathrm{~m}$ behind the quarry face, (c) GPR data after the deterministic deconvolution, the trapezoidal bandpass filtering, and the AGC scaling. Open dots on $3 b$ and $3 c$ represent rod locations as shown on $3 a$.

ministic deconvolution processing step improved the quality of GPR images over images that are conventionally processed using only scaling and bandpass filtering.

One experiment measured the response of six vertically aligned steel rods in quarry face BSG3 (Figure 3a). Time-todepth conversions are based on EM wave propagation velocities calculated from moveout curves on the CMP data. We acquired GPR data along a 6-m line, $1 \mathrm{~m}$ behind the quarry face containing the steel rods. The conductive rods appear as hyperbolas on the GPR section. Although the apex of the hyperbolas should indicate the precise location of the rods, the locations (horizontal and vertical) of the apexes of the hyperbola on the nondeconvolved GPR data are skewed compared to the true rod locations (Figure $3 b)$. The average velocity of EM wave propagation in the carbonate strata at this site is $0.1 \mathrm{~m} / \mathrm{ns}$ which, for the 50 -, $100-$, 200- and 400-MHz antennas, equates to a quarter wavelength vertical resolution of $0.5,0.25,0.1$, and $0.06 \mathrm{~m}$, respectively. Two reflectors closer than $0.06 \mathrm{~m}$ are not resolvable. With this limitation in resolution, the six rods on the nondeconvolved GPR section can only be located within about $0.1 \mathrm{~m}$ vertically and $0.2 \mathrm{~m}$ horizontally (Figure 3b).

In contrast, after using deterministic deconvolution in the processing, the apexes of the four shallowest hyperbolas distinctly and correctly represent the locations of the corresponding four rods both horizontally and vertically (Figure 3c). Using a normal moveout velocity calculated from a nearby CMP gather $(0.097 \mathrm{~m} / \mathrm{ns})$, the true depths of the first four rods can be located within a few centimeters from the GPR data. It is also now possible to locate the two deepest rods even though, theoretically, they are too deep to detect (considering their size and penetration limitations for antennas of this frequency) and not uniquely detectable since they are separated by less than one-quarter wavelength.

The improvement in resolution after deterministic deconvolution is further demonstrated by comparison of deconvolved and nondeconvolved GPR sections with geologic features mapped along the face of quarry exposure (Figure 4 shows a portion of a mapped quarry face). GPR data were again acquired along a line $1 \mathrm{~m}$ behind the quarry face. CMP data with $60-$ trace gathers and maximum source and receiver antenna separation of 0.6 $\mathrm{m}$ were acquired at 11 intersection points of the GPR survey grid. Timeto-depth conversions are based on EM wave propagation velocities calculated from moveout curves on the CMP data. Accuracy of these conversions was confirmed by comparing surveyed horizontal rod locations along the BSG1 face with depths calculated from the GPR data.

Letters assigned to beds to facilitate comparison between the outcrop and GPR response. Orange dots show the locations of the horizontal steel bar experiments. Edge effects caused by the quarry face were not evident on the profile even though it was taken only $1 \mathrm{~m}$ behind the quarry face. This observation was made after comparing two GPR sections acquired along the same line before and after the blast- 


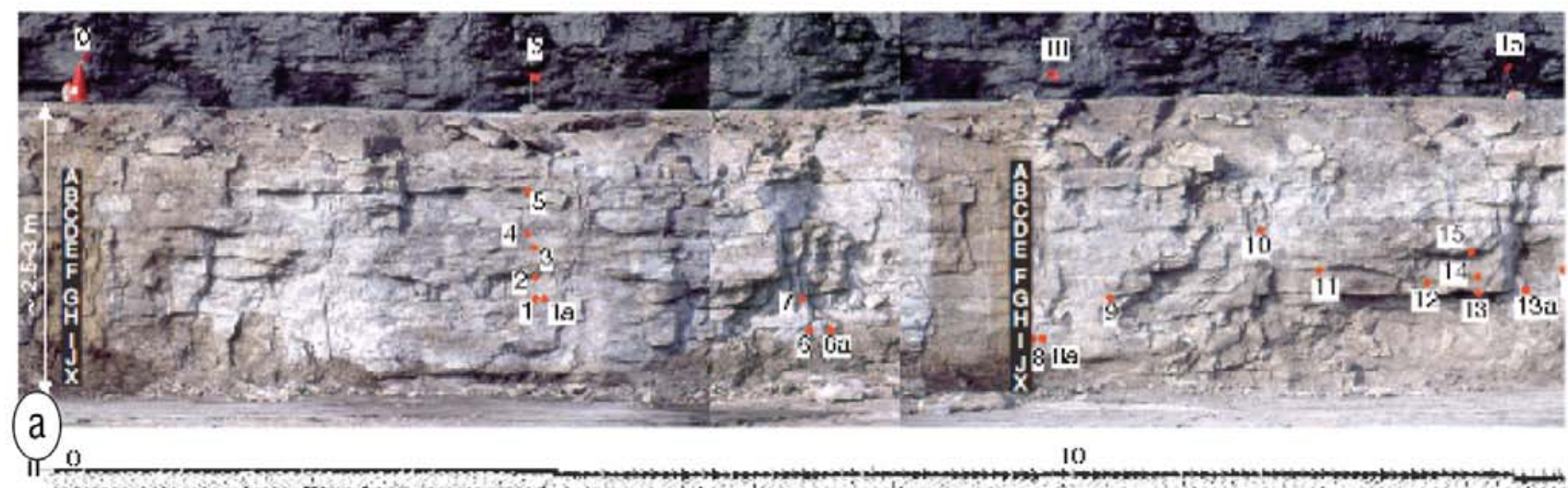

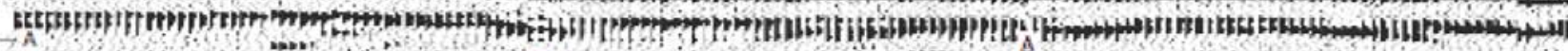

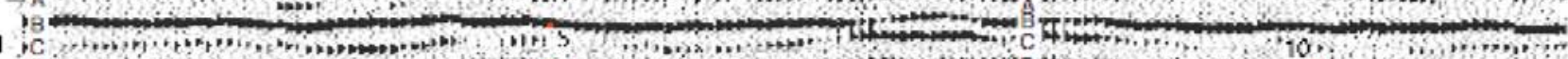

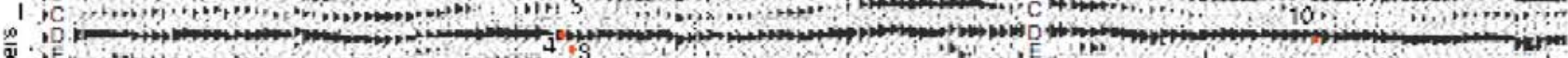

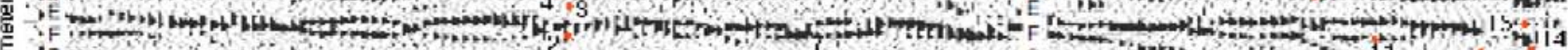
ig ?G Gom

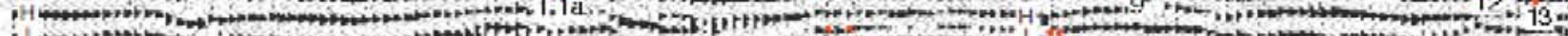

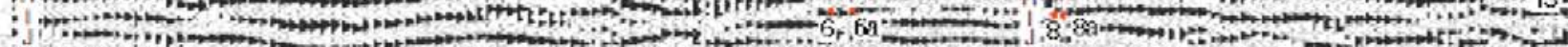

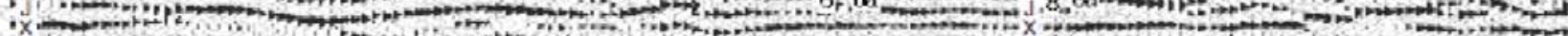

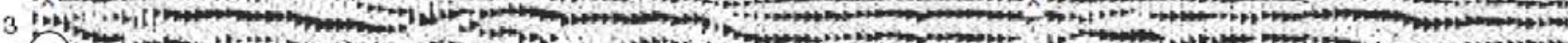

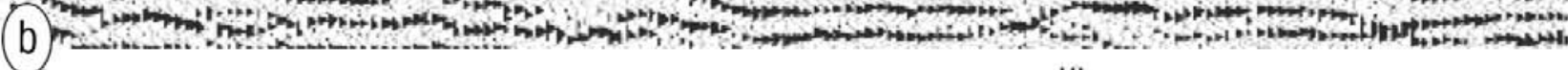
11 III

0 H.

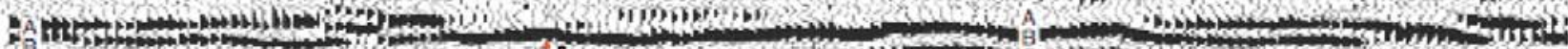

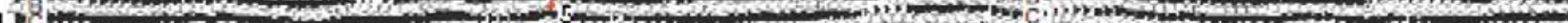

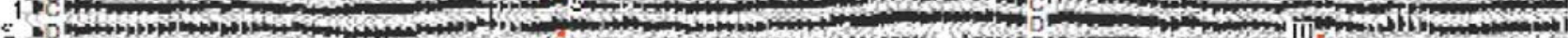

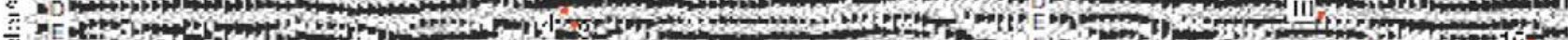
(1)

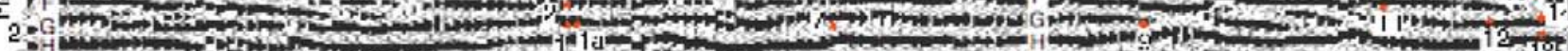

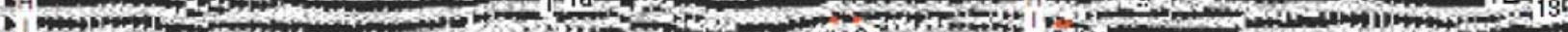

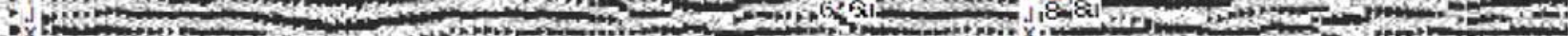
$x$ -

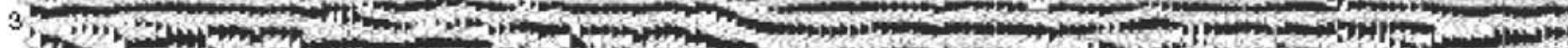

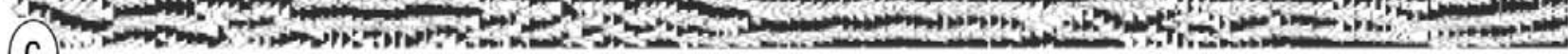
(C)

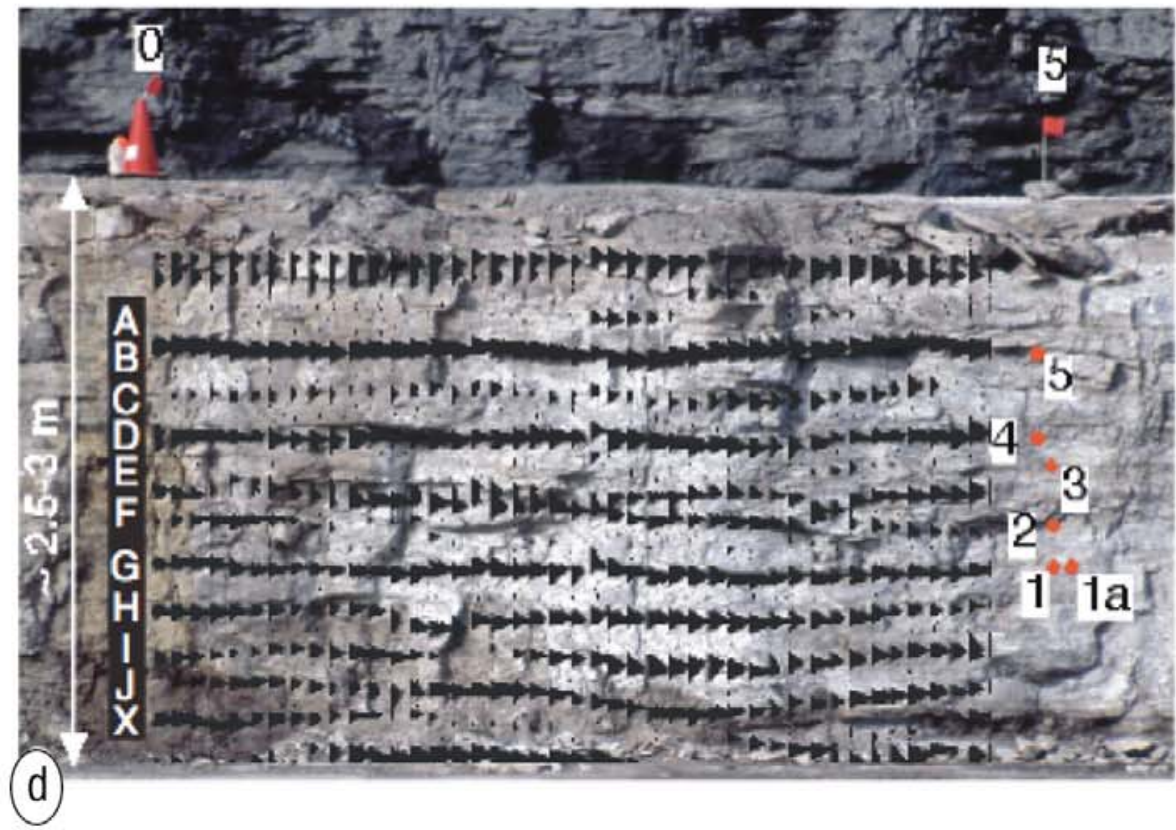

Figure 4. Comparison of GPR data from a portion (0 to approximately $15 \mathrm{~m}$ ) of the BSG1 quarry face (a), after deterministic deconvolution processing (b), and the same GPR data after just AGC scaling and bandpass filtering (c), which are the type of data conventionally used for interpretation in sedimentary studies. Note the complexity in (c) compared to (b). GPR reflections on (b) (after deterministic deconvolution) are easier to directly tie to geologic features on the photo mosaic and are confirmed by steel rod data (orange dots). (d) A portion of the BSG1 quarry face shown in $4 a$ with deconvolved GPR data directly overlain on the rocks. There is a high degree of direct correlation of GPR reflections with bedding and lithologic changes. 


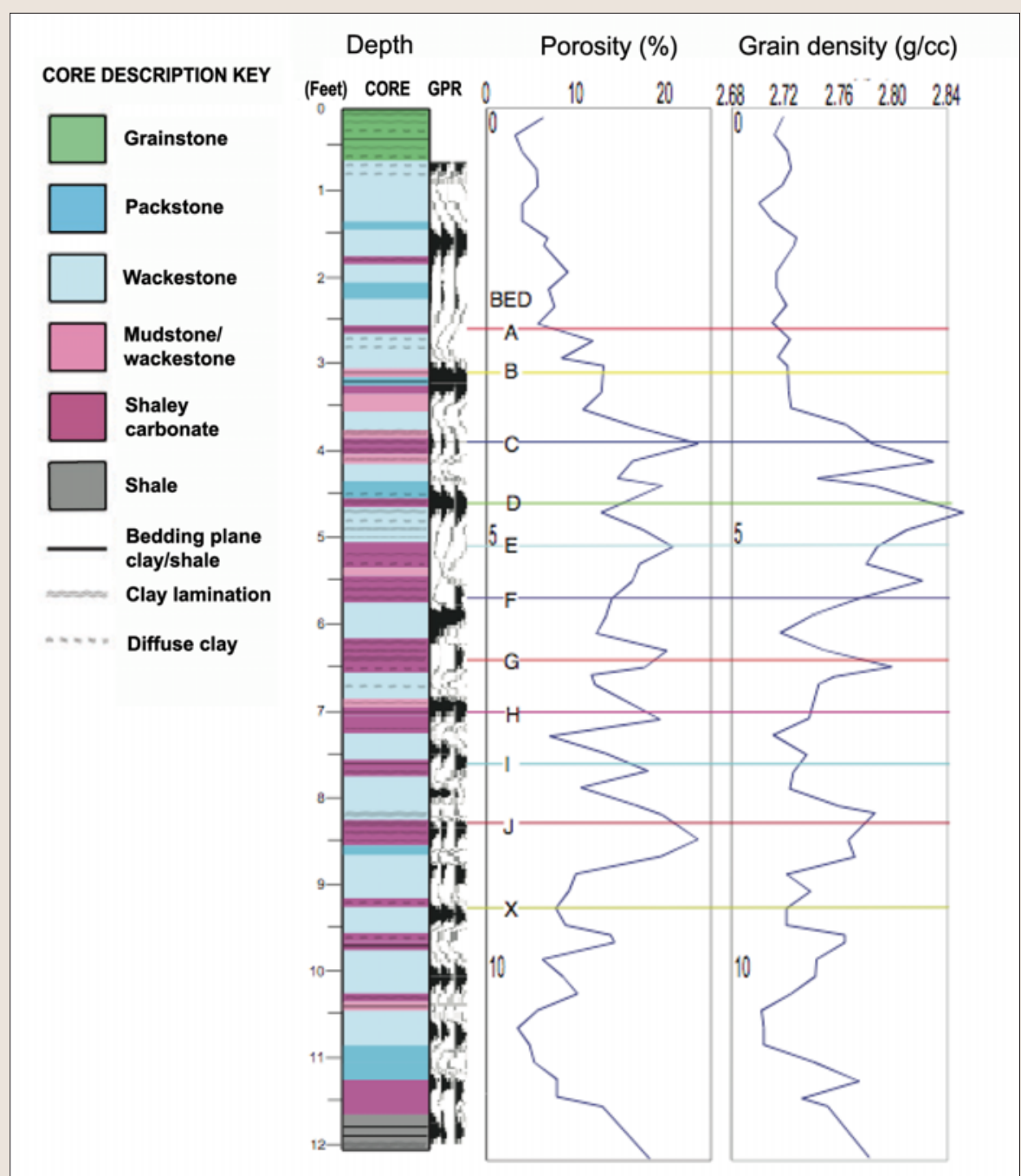

Figure 5. Lithologic features, rock properties, and GPR response for a core from the BSG2 quarry face. Increasing grain density is generally indicative of increase in amount of dolomite (also confirmed by petrographic study). Increased porosity is generally associated with dolomite; much of the dolomite is associated with clay-rich intervals. Higher porosity also is associated with partings along clay-rich horizons.

ing of successive quarry faces (Xia et al., 2003). Because of the limited temporal resolution of nondeconvolved GPR data (Figure 4c), locations of some of the horizontal steel rods on the BSG1 face cannot be confidently determined. As mentioned before, the maximum potential vertical resolution is around $0.1 \mathrm{~m}$ at this site. Because GPR data after deterministic deconvolution (Figure $4 \mathrm{~b}$ ) clearly defined beds that are about 0.18 -m thick (top three beds) and $0.15 \mathrm{~m}$ thick (the bed between $\mathrm{G}$ and $\mathrm{H}$ under the 10-m flag), resolution of the GPR image appears to have increased by at least $50 \%$.

A comparison between some general features exhibited on the quarry face (Figure 4a) with the deconvolved section (Figure $4 \mathrm{~b}$ ) and then with the nondeconvolved section (Figure 4c) further highlights the effectiveness of the deterministic deconvolution. In addition, Figure $4 \mathrm{~d}$ shows a portion of the quarry face with the deconvolved GPR response directly overlain on the rocks further illustrating the effectiveness of deconvolved data to accurately represent the geologic features.

Beds B, D, G, and X are distinct, laterally traceable bedding planes characterized by relatively thick shale partings. Consistent with reflectivity estimations, the carbonate-shale contacts should be, and are, strong, laterally continuous reflections on deconvolved GPR sections. However, these horizons are neither distinctly identifiable nor laterally continuous on nondeconvolved sections. $\mathrm{A}$ and $\mathrm{C}$ are distinct, laterally traceable horizons on the BSG1 outcrop characterized by lateral variations in shale concentration. Based on the lateral variations in shale concentration, the GPR image of these horizons might be expected to possess some variability in reflection wavelet character as a function of differing shale concentrations and associated differences in rock properties. On deconvolved GPR sections, A and $C$ are confidently identified and their reflection character varies laterally. Identification of $\mathrm{A}$ and $\mathrm{C}$ on nondeconvolved sections is more problematic and requires identification of the more distinct $\mathrm{B}$ and $\mathrm{D}$ bedding planes to use as a guide. However, the $\mathrm{B}$ and $\mathrm{D}$ beds are also a challenge to identify on nondeconvolved sections. $\mathrm{H}, \mathrm{I}$, and $\mathrm{J}$ are distinct horizons that are traceable with varying degrees of confidence along the BSG1 quarry face due to lateral variability in bedding plane shale amounts and pinching and swelling geometries. Therefore, reflection characteristics of these horizons on GPR sections should include laterally variable reflection amplitudes and geometric complexities. The general locations of $\mathrm{H}$, I, and J can be confidently located on the deconvolved section when aided by location of the more distinct laterally continuous $\mathrm{E}$ and $\mathrm{X}$ bedding horizons. As expected from mapping of the quarry face, $\mathrm{H}$, $\mathrm{I}$, and $\mathrm{J}$ possess lateral variation in reflection character and geometric complexity on deconvolved data. In contrast, H, I, and J are virtually impossible to confidently locate on nondeconvolved data due to overall complexity associated with wavelet interference and noise on GPR data at those depths.

Finally, the beds between F and D (including E and several unlabeled horizons) are the most difficult to trace in outcrop due to bedding planes that die out laterally, highly variable shale content along bedding planes and geometric variability. Accordingly, GPR reflection characteristics and geometry for these horizons is very complex between $\mathrm{F}$ and D. Confident identification of the general location of these complex horizons between $\mathrm{F}$ and $\mathrm{D}$ horizons provide the opportunity for further examination of the detailed associations of GPR reflection character and geology changes. In contrast, even speculative identification of just the general location of these complex bedded horizons between $\mathrm{F}$ and D horizons is virtually impossible on nondeconvolved sections.

Deterministic deconvolution appears to enhance true amplitude of some reflections, which is consistent with stratigraphic/sedimentologic features on the quarry face. For example, distinct and continuous horizons B and D that contain consistent shale concentration at bedding planes on the quarry face are represented by reflections with higher amplitude and greater coherence. In contrast, A and C, charac- 

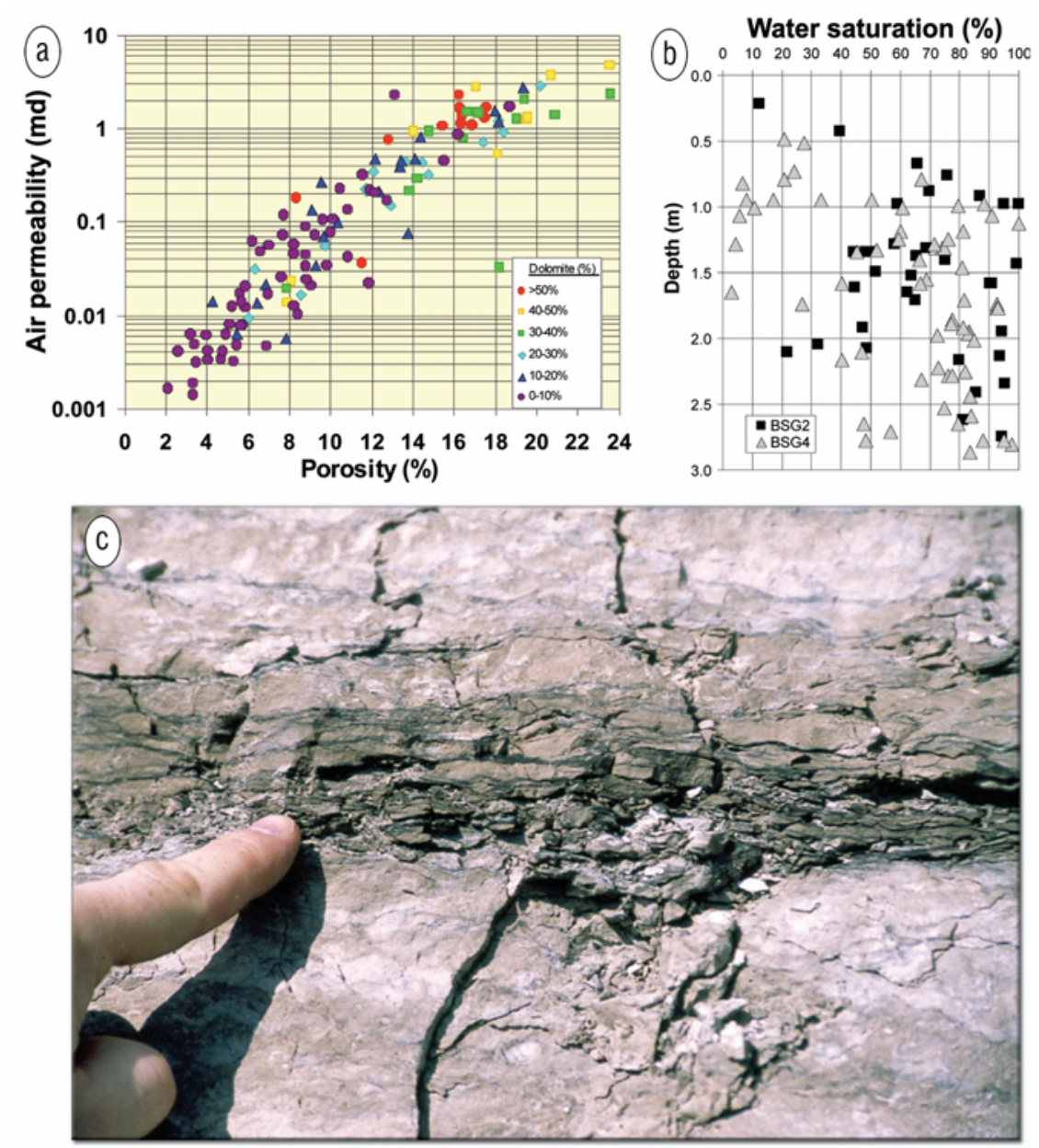

Figure 6. (a) Plot of porosity and air permeability showing increase in porosity and hydraulic permeability with increasing dolomite content. Symbols indicate different dolomite contents. (b) Water saturations measured from outcrop samples along quarry faces exposed at BSG2 and BSG4. Water saturations increase in shaly beds and in the interval immediately overlying shale beds. Water saturations drop underneath shale beds. (c) Shale horizon showing wispy shale laminae and higher water saturation evident from darker color.

terized by lateral variations in shale concentration are represented by reflections with lower amplitudes and less continuity.

Rock properties and forward modeling of GPR response. Exposed quarry faces and cores taken within the grid were described in detail for lithofacies characteristics that may be important for GPR response. Quarry face and core descriptions were used to visually represent the rocks, to compare rock properties with GPR profiles from quarry faces, and to model petrophysical properties for dielectric constant modeling.

Dielectric permittivity, $\varepsilon$, or expressed as dielectric constant, $\kappa\left(=\varepsilon / \varepsilon_{\mathrm{o}}\right.$ where $\varepsilon_{\mathrm{o}}$ is the vacuum permittivity constant), is a critical GPR parameter because it controls the electromagnetic wave propagation velocity through a material, the reflection coefficients at interfaces, and affects the vertical and horizontal imaging resolution. Dielectric constants in rocks are primarily a function of mineralogy, porosity, pore fluids, frequency, geometries, and potential electrochemical interactions between the components.

The clay minerals present in the Farley Limestone are mainly illite / mica, kaolinite, and trace smectite (Mckirahan et al., 2000). The dielectric constant for illite/mica is 6.4, kaolinite is 11.8 (Olhoeft, 1989), and calcite and dolomite ranges from 6.4 to 8.5 (Olhoeft, 1989; Martinez and Byrnes, 2001). Also, shales typically have dielectric constants that range from 5 to 15 (Davis and Annan, 1989; Daniels, 1996), and the calcareous shales in the study area have dielectric constants that range from 6 (dry) to 6-13 (saturated) as measured by Martinez and Byrnes (2001). Therefore, although strong GPR reflections occur at the locations of shaly horizons, the similarity in dielectric constants at the study site indicates that mineralogy alone cannot account for the strong reflections that occur.

A suite of petrophysical properties were measured on samples from cores and the outcrop faces and combined with petrographic study to further understand the lithologic and petrophysical controls on GPR response. Figure 5 illustrates lithologies, porosity, and grain density (dolomite) relationships and associated GPR response for a core within the grid, and is representative of the general consistency in rock properties and GPR response between all cores taken within the grid. Core plug petrophysical analyses indicate there is a good correlation between porosity $(\phi)$ and hydraulic permeability $(\kappa)$ for all beds. Increasing dolomitization is associated with increasing $\phi$ for $\phi>10 \%$ (Figure 6a). Variance in density for any given $\phi$ is not strongly influenced by argillaceousness. However, horizontal partings along shale beds also create high porosity and permeability. Core plug and miniprobe permeability measurements also indicate that the middle portion of the quarry exposures generally has higher porosity and permeability values as compared to the upper and lower (to $3.5 \mathrm{~m}$ depth) portions of the studied interval. Porosity, with a dielectric constant of 1 when air-filled, can have a significant influence on GPR response (Martinez and Byrnes, 2001). However, examination of Figure 5 indicates that there is no clear-cut correlation between strong GPR peak reflections and bulk mineralogy and porosity changes. Although several strong peaks appear to be closely associated with increased porosity and grain density (increasing dolomite content), other strong peaks are observed where: (1) no bulk density or porosity change exists; (2) porosity changes are both increasing and decreasing with depth; (3) dolomite content is both increasing and decreasing; (4) dolomite content and porosity are both increasing and decreasing in opposite directions. Therefore, bulk mineralogy and porosity alone are not the dominant variables influencing GPR response.

Knight (2001) and Martinez and Byrnes (2001) also showed the significant influence of water (standard dielectric constant value of 81 at $20^{\circ} \mathrm{C}$ ) on GPR response. Water saturations measured on outcrop samples from the BSG2 and BSG4 quarry faces (Figure 6b) indicate that water saturation increases with depth and exhibits significant increase within shaly intervals and in the $0.01-0.03 \mathrm{~m}$ interval imme- 


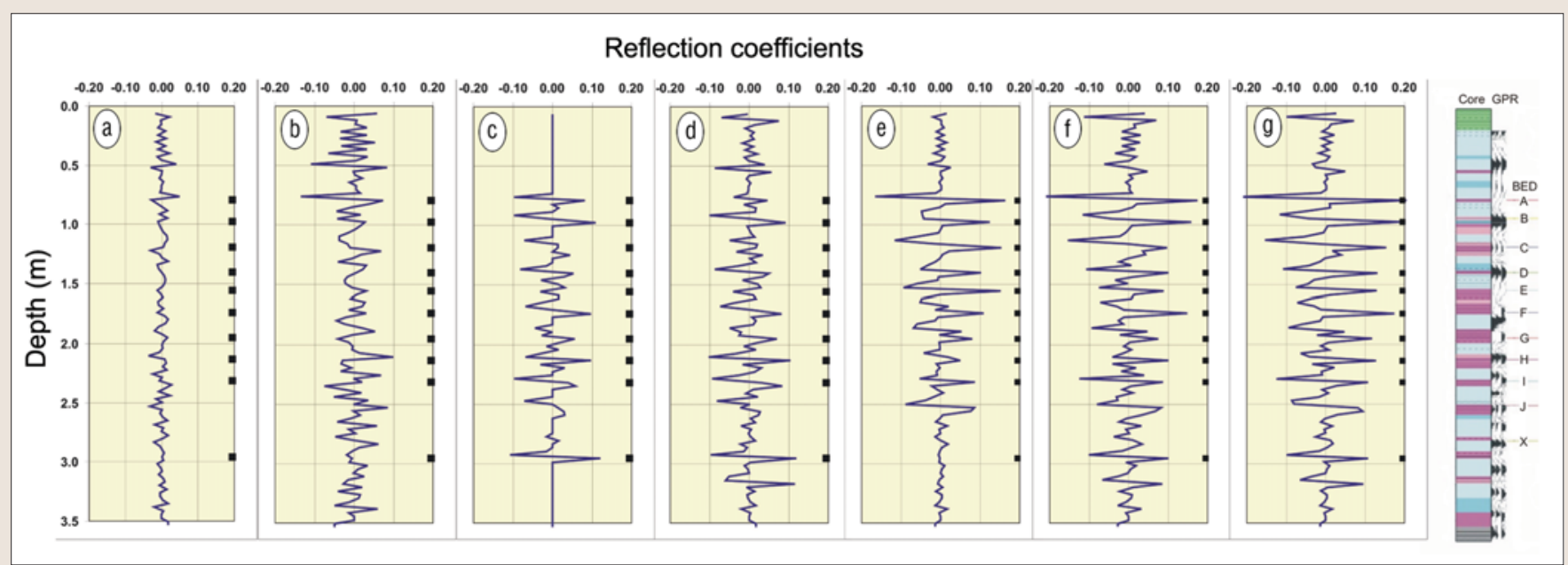

Figure 7. Reflection coefficient profiles calculated using a time-propagation (TP) model of the strata at the quarry site for a specific core location equivalent to a single GPR trace. Models shown are: (a) $\phi=V, X=L s, S_{w}=0 \% ;(b) \phi=V, X=L s, S_{w}=100 \% ;(c) \phi=0 \%, X=V, S_{w}=0 \% ;(d) \phi=V$, $X=V, S_{w}=0 \%$; (e) $\phi=V, X=L s, S_{w}=V ;(f) \phi=V, X=V, S_{w}=60 \% V ;(g) \phi=V, X=V, S_{w}=40 \% V ;$ where $\phi=$ porosity (\%), $S_{w}=$ water saturation $(\%)$, $X=$ mineral composition, $L s=$ limestone, $V=$ variable, $40 \% \mathrm{~V}=$ variable $S_{w}$ with carbonate $S_{w}=40 \%, 60 \% \mathrm{~V}=$ variable $S_{w}$ with carbonate $S_{w}=60 \%$.

diately overlying shaly intervals (Figure 6c). These shaly horizons consist primarily of closely spaced thin and wispy shale laminae occurring in carbonate lithology that is similar in composition to that of the vertically adjacent clean (and thicker) carbonate beds. Near-complete water saturation at the tops of most of the prominent shaly horizons was evidenced on the outcrop by wet or seeping water conditions at those horizons.

To better understand the observed GPR response and variables that control the response, dielectric permittivity and reflectivity modeling was conducted. Dielectric permittivity mixing models allow prediction of bulk dielectric properties of complex earth materials based on the dielectric properties of constituent materials. A dielectric mixing model that is highly useful and easy to construct for geologic materials is the time-propagation (TP) model, a volumetric-type dielectric mixing model. The TP mixing model has been shown to be effective in carbonate rocks from the study site area (Martinez and Byrnes, 2001) and in carbonates rocks in general (Seleznez et al., 2004) where the mathematical equation for the TP dielectric mixing model is:

$$
\varepsilon_{\mathrm{r}}=\left[\Sigma \mathrm{V}_{\mathrm{i}}\left(\varepsilon_{\mathrm{ri}}\right)^{1 / 2}\right]^{2}
$$

where $\mathrm{V}_{\mathrm{i}}$ and $\varepsilon_{\mathrm{ri}}$ are the bulk volume fraction and dielectric permittivity of the ith component (Knoll, 1996). This model does not account for variations in frequency and is valid only for low conductivity $(\sigma<10 \mathrm{mS} / \mathrm{m})$, nonmagnetic (i.e., $u_{\mathrm{r}}=1$ ) materials, which is the case for the rocks in our study.

Electromagnetic impedance equals the square root of dielectric permittivity. Using EM impedance, the reflection coefficient (RC) of GPR signals in nonmagnetic material can be calculated using the relationship:

$$
\begin{aligned}
& \mathrm{RC}=\left[\left(\varepsilon_{\mathrm{r}}\right)^{1 / 2}-\left(\varepsilon_{\mathrm{r} 2}\right)^{1 / 2}\right] / \\
& {\left[\left(\varepsilon_{\mathrm{r}}\right)^{1 / 2}+\left(\varepsilon_{\mathrm{r} 2}\right)^{1 / 2}\right]}
\end{aligned}
$$

where $\varepsilon_{\mathrm{r}}$ is the dielectric permittivity of the upper media, and $\varepsilon_{\mathrm{r} 2}$ is the dielectric permittivity of the lower media. This equation describes the strength of single-fold reflections at interfaces of materials of different lithology or water saturations (i.e., different bulk dielectric permittivities).

The mixing of the geologic materials at the study site within the range of $0-25 \%$ porosity (as measured from core plugs), and for water saturations ranging from dry to watersaturated, produces a full wavelength of a $400 \mathrm{MHz}$ signal that ranges from 0.17 to $0.28 \mathrm{~m}$. This vertical resolution limits the ability to quantitatively analyze the properties of beds of less than $0.17 \mathrm{~m}$ from the waveform properties along a trace. However, the reflection coefficient (RC) can still be used to investigate differences in properties of juxtaposed beds and an assumption of the properties of a bed can be used to estimate properties of juxtaposed beds. The prominent peaks on the GPR sections that correlate with shaly intervals (Figure 6c) can be characterized as exhibiting a peak reflectivity signal-to-background of greater than 2 standard deviations above the background.

Figure 7 illustrates the modeled response of a single GPR trace calculated using equations 1 and 2 above. The mean of all RC values is zero. For the observed porosity changes with depth, assuming mineralogy and water saturation $\left(S_{w}\right)$ are constant, modeled $R C$ values for the known bed depths exhibit values within $0.5 \sigma$ (standard deviation) of the mean $\mathrm{RC}$ value for the entire interval, $\mathrm{RC}_{\mathrm{m}}$. This statistic indicates that if porosity alone changed, the produced bed reflection coefficients would not differ statistically significantly from "background" RC variance (RC noise).

To model the influence of mineralogy, we assume dielectric constants of 7 and 12 for the carbonate and shale minerals, respectively, and assign mineral fractions to each 0.03 $m$ interval based on core description. Holding porosity constant at the mean porosity of $\phi=11.7 \%$ and $\mathrm{S}_{\mathrm{w}}$ constant at any saturation, 5 of the 11 beds exhibit $R C$ values greater than $2 \sigma$ above the $R_{\mathrm{m}}$ and 9 of the 11 beds exhibit RC values greater than $1 \sigma$ above the $\mathrm{RC}_{\mathrm{m}}$. This can be interpreted to indicate that the observed bed reflections result, in part, from mineralogy changes.

Because of the high $\varepsilon_{\mathrm{r}}$ of water $\left(\varepsilon_{\mathrm{r}}=81\right)$, water saturation and porosity play a critical role in bulk $\varepsilon_{\mathrm{r}}$ (Knight, 2001; Martinez and Byrnes, 2001). Martinez and Byrnes showed the significant influence of water saturation and porosity and the lesser influence of mineralogy on bulk dielectric constant, $\varepsilon_{\mathrm{r}}$, and concluded water saturation and porosity are primary controls on GPR response, including two way traveltime, reflection coefficient amplitude across interfaces of different materials, and vertical and horizontal imaging resolution. A strong GPR response is generally associated with the contact between overlying and underlying, lower $\mathrm{S}_{\mathrm{w}}$, car- 
bonate beds, and the higher porosity wet dolomite intervals and underlying wet shaly intervals. Clean carbonates with less dolomite are less porous and GPR response tends to be weaker.

Measurements of water saturations indicate that the thick-bedded carbonates had water saturations ranging from $40-60 \%$ whereas the shaly intervals exhibit saturations of $90-100 \%$. Water was also observed to perch on the shaly intervals increasing water saturations for strata $0.0-0.06 \mathrm{~m}$ above the top of the shaly interval to saturations of $S_{w}=$ $60-100 \%$. Figure 7 shows two models where average carbonate interval $S_{w}=40 \%$ and $60 \%$, respectively, with shaly intervals having $S_{w}=100 \%$ and the thin $(0.03-0.06 \mathrm{~m})$ overlying carbonate interval assigned an $S_{w}$ equal to the average $S_{w}+20 \%$ (i.e. $S_{w}=60 \%$ and $S_{w}=80 \%$ ). For these models, 7 of the 11 beds exhibit RC values greater than $2 \sigma$ above the $\mathrm{RC}_{\mathrm{m}}$ and 11 of the 11 beds exhibit RC values greater than $1 \sigma$ above the $\mathrm{RC}_{\mathrm{m}}$. The 11 identified beds represent the 11 highest RC values in the complete interval. If these $11 \mathrm{RC}$ values are removed from the total population of $\mathrm{RC}$ values and a standard deviation is calculated for the remaining $\mathrm{RC}$ values, $\mathrm{RC}_{\mathrm{mnb}}$, the mean $\mathrm{RC}$ of the 11 beds is $4 \sigma$ greater than the $\mathrm{RC}_{\mathrm{mnb}}$. Because of a decreasing difference in $S_{\mathrm{w}}$ between the carbonate and shaly beds, for average carbonate $S_{w}=$ $60 \%$, the mean $\mathrm{RC}$ of the 11 beds is $3.2 \sigma$ greater than the $\mathrm{RC}_{\mathrm{mnb}}$. These significant differences between the $\mathrm{RC}$ of the shaly intervals and the "background" reflection noise supports the interpretation that water in and immediately overlying shaly intervals, and high porosity in dolomite that occurs adjacent to shale horizons combine to be primary controls on strong GPR reflections.

In comparing different models, one model that involves variable mineralogy and $S_{w}$ but a constant porosity (near $\phi=11.7 \%$ ) exhibits an $\mathrm{RC}$ value for the beds $\mathrm{RC}_{\mathrm{mb}}$ that is $88 \%$ of the $\mathrm{RC}_{\mathrm{mb}}$ for the complete model with variable mineralogy, $\phi$, and $S_{w}$. The $R_{m b}$ for a model with variable $S_{w}$ and $\phi$ but constant mineralogy exhibits an $\mathrm{RC}_{\mathrm{mb}} 77 \%$ of the complete model. In contrast, the models where $\mathrm{S}_{\mathrm{w}}$ was constant and only mineralogy varied, or where mineralogy and $\phi$ both varied, exhibit $\mathrm{RC}_{\mathrm{mb}}$ values $38 \%$ and $34 \%$ of the complete model, respectively. These results indicate that the RC of thin-bedded rock layers are sufficiently different so that differences in mineralogy or porosity between beds can be detected even if saturations remain constant.

These results provide confidence for further interpreting details on the collected GPR data that were not obvious in the field. Discontinuous and subtle reflectors between the main traceable layers are likely areas of water-saturated shale partings and/or porous dolomite intervals (at least partially saturated) that affect heterogeneity within the setting. Results from forward modeling, compared to and calibrated with actual GPR response from the grid, can in turn be used for inversely modeling expected reflection coefficients, twoway traveltimes, and vertical and spatial imaging. Inverse modeling results can be used to predict lithologic, porosity, and resultant water saturation state and heterogeneity at high resolution based on GPR attributes away from control points.

Conclusions. A quarry with exposures of Pennsylvanian carbonates (limestone, dolomite) and interbedded shale was selected to conduct GPR experiments incorporating lithologic, diagenetic, porosity, hydraulic permeability, minipermeameter, water saturation, and dielectric constant data. A new technique incorporated the use of steel rods inserted horizontally into quarry faces to provide direct ground truth of reflections and reflectors.
Deterministic deconvolution, using the acquired instrument wavelet, successfully suppressed narrow-band sourcewavelet interference and resulted in clearer depiction of geologic features over conventionally processed GPR data (only scaled and AGC bandpass-filtered) as confirmed by detailed study of quarry faces and conductive steel bar experiments. Experiments also confirmed that out-of-plane effects, multiples, and other noise on GPR data are minimal or nonexistent at the study site. Geologic features identified on quarry walls ( 3-3.5 m vertical exposures), even those as closely spaced as $\sim 10 \mathrm{~cm}$, are resolvable, confidently correlated, and accurately represented by reflection character on the GPR section incorporating the deterministic deconvolution processing. Time-to-depth conversion based on EM wave propagation velocities calculated from moveout curves on CMP data are generally accurate as confirmed by steel bar experiments. However, petrophysical measurements indicate that the middle of the studied quarry exposure has generally higher porosity and permeability values as compared to the upper and lower portions of the studied interval. These data can be used for refining velocity calculations.

Petrographic and petrophysical data are critical for determining which factors most influence dielectric permittivities. These data indicate that clay and carbonate mineralogy alone at the study site cannot account for the strong reflections that occur. Petrophysical properties of the rocks in all layers are highly correlated including hydraulic permeability with porosity and porosity with grain density (reflecting dolomitization). Strong GPR reflections at shale bed contacts are interpreted to result from high porosity/permeability along clay/shale beds and partings, higher porosity/permeability associated with dolomitization of the original limestone that occurs adjacent to clay bedding planes/partings and the high water saturation states (approaching 100\%) associated with those horizons. In contrast, clean carbonates with less dolomite are less porous/permeable, exhibit less water saturation states (40-60\%), and GPR response tends to be weaker.

A volumetric-type dielectric-mixing model (time propagation) allows prediction of bulk dielectric properties based on the dielectric properties of constituent materials. Results using this forward modeling approach show that a dry or fully water-saturated outcrop does not exhibit the observed GPR response. A modeled response for a profile with $\sim 40 \%-60 \%$ water saturation in the limestone and $100 \%$ in the clay/shale beds exhibits strong reflectance coefficient values at the clay/shale beds and matches observed GPR response indicating water saturation and porosity are primary controls on GPR response.

The conductive steel rod experiments, petrographic and petrophysical data, and forward modeling were critical for identifying the controls on GPR reflection character. These steps are essential for inversely predicting rock properties in sedimentary strata from GPR response using attribute analysis.

Finally, an understanding of diagenetic effects is critical for interpreting GPR in carbonate settings, as diagenesis can have a strong influence on reflection character. In our study, diagenesis (dolomitization, increase in porosity/permeability) was closely associated with stratigraphic features (clay/shale bedding planes and partings), thereby enhancing the stratigraphic signature on GPR data. However, in many carbonate settings, diagenetic processes occur independent of, and even obscure (e.g., cut across), stratigraphic/sedimentologic features. In such instances, GPR reflections may be indicative of diagenesis, and not origi- 
nal sedimentologic/stratigraphic features.

Suggested reading. Ground-Penetrating Radar by Annan (Sensors and Software Inc., 1996). "Surface-penetrating radar" by Daniels (in IEE Radar, Sonar, Navigation, and Avionics series 6, Institute of Electrical Engineers, 1996). "Ground-penetrating radar for high-resolution mapping of soil and rock stratigraphy" by Davis and Annan (Geophysical Prospecting, 1989). "Two-sided deconvolution: A method to improve the temporal resolution in radar data" by Gottsche et al. (EAGE 1994 Extended Abstracts). "Ground-penetrating radar for environmental applications" by Knight (Annual Review Earth Planetary Science, 2001). "A petrophysical basis for ground-penetrating radar and very early time electromagnetics, electrical properties of sand-clay mixtures" by Knoll (PhD dissertation, University of British Columbia, 1996). "Die Herleitung des logarithmischen Mischungsgesetz es aus allgemeinen Prinzipien der stationären Strömung" by Lichtenecker and Rother (Physikalische Zeitschrift, 1931). "Modeling dielectric-constant values of geologic materials_-An aid to ground-penetrating radar data collection and interpretation" by Martinez and Byrnes (in Current Research in Earth Sciences, Kansas Geological Survey Bulletin 247, part 1, 2001). "Sequence stratigraphy of the Lane-Island Creek Shales and the Farley Limestone in Northeastern Kansas and geologic factors affecting the quality of limestone aggregates" by McKirahan et al. (K-TRAN Report No. KU-97-1, 2000). "Delineation of a complexly dipping temperate glacier bed using short-pulse radar arrays" by Moran et al. (Journal of Glaciology, 2000). "Ground-penetrating radar and its use in sedimentology: Principles, problems, and progress" by Neal (Earth Science Reviews, 2004). "Source signature deconvolution of ground-penetration radar data" by Neves (Revista Brasileira de Geofisica, 1995). "Electrical properties of rocks" by Olhoeft (in Physical Properties of Rocks and Minerals, Hemisphere Publishing Corporation, 1989). "Mixed-phase deconvolution of seismic and ground-penetrating radar data" by Porsani and Ursin (SEG 1996 Expanded Abstracts). "Dielectric mixing laws for fully and partially saturated carbonate rocks" by Seleznev et al. (Proceeding of the Society of Professional Well Log Analysts 45 ${ }^{\text {th }}$ Annual Logging Symposium, 2004). "Deconvolution of ground-probing radar data" by Todoeschuck et al. (in Ground-Penetrating Radar, Geological Survey of Canada, 1992). "Subsurface radar propagation deconvolution" by Turner (GEOPHYSICS, 1994). "Application of deterministic deconvolution of ground-penetrating radar data in a study of carbonate strata" by Xia et al. (Journal of Applied Geophysics, 2004). "Improving ground-penetrating radar data in sedimentary rocks using deterministic deconvolution" by Xia et al. (Journal of Applied Geophysics, 2003). Seismic Data Processing by Yilmaz (SEG, 1987). TLE

Acknowledgments: We thank Shawnee Rock, Bonner Springs, Kansas, especially Frank Rockers, and Owen Crome, for kindly providing access to the quarry study site, cooperating in design of the project, and assistance during data acquisition. Chris Liner is thanked for his review of the paper. This study was funded by the National Science Foundation (EAR 9912062).

Corresponding author: evanf@kgs.ku.edu 